\title{
$\mathrm{Eu}$ - Le Bois l'Abbé, parcelle 17
}

\section{Laurence Ciezar-Epailly}

URL : http://journals.openedition.org/adlfi/8016

ISSN : 2114-0502

Éditeur

Ministère de la culture

\section{Référence électronique}

Laurence Ciezar-Epailly, «Eu - Le Bois l'Abbé, parcelle 17 », ADLFI. Archéologie de la France -

Informations [En ligne], Haute-Normandie, mis en ligne le 01 mars 2005, consulté le 03 mai 2019. URL: http://journals.openedition.org/adlfi/8016

Ce document a été généré automatiquement le 3 mai 2019.

(c) Ministère de la Culture et de la Communication, CNRS 


\title{
Eu - Le Bois l'Abbé, parcelle 17
}

\author{
Laurence Ciezar-Epailly
}

Identifiant de l'opération archéologique : 76255001

Date de l'opération : 2005 (SD)

1 Le sondage a permis de faire la jonction entre les sondages 2003 et 2004, où avait été observée la voirie axée nord-sud. Cette dernière, reconnue sur une vingtaine de mètres de longueur est large de 2,45 m. Son empierrement est composé de rognons de silex d'un diamètre moyen de $7 \mathrm{~cm}$ à $8 \mathrm{~cm}$. On constate ici un rétrécissement de l'axe en direction du sud. Les différences observées sur la nature et les caractéristiques de l'empierrement sont à ce jour sans réponse (pas de petits galets dans le sondage 2005).

2 Parmi les autre structures on retiendra la présence d'un mur maçonné perpendiculaire à la voirie, comme les deux découverts de part et d'autre dans les sondages des années précédentes, et un niveau empierré (fondation? Sol ?). Le mobilier recueilli s'échelonne du $\mathrm{I}^{\mathrm{er}}$ s. au III $\mathrm{e}$.

3 Dans l'état actuel des recherches, les structures mises au jour ne peuvent être replacées plus précisément dans le contexte général antique de l'agglomération secondaire.

4 CIEZAR-EPAILLY Laurence, d'après David SOCHAT 
INDEX

Index chronologique : Empire romain

Index géographique : Haute-Normandie, Seine-Maritime (76), Eu

Thèmes : maçonnerie, mur, silex, voirie

operation Sondage (SD)

\section{AUTEURS}

\section{LAURENCE CIEZAR-EPAILLY}

SRA 